\title{
Wool Carpet Dye Adsorption on Nanoporous Carbon Materials Derived from Agro-Product
}

\author{
Raja Ram Pradhananga ${ }^{1}$, Laxmi Adhikari ${ }^{2}$, Rekha Goswami Shrestha ${ }^{3}$, \\ Mandira Pradhananga Adhikari ${ }^{2}$, Rinita Rajbhandari ${ }^{4}$, Katsuhiko Ariga ${ }^{3}$ \\ and Lok Kumar Shrestha ${ }^{3, *}$
}

1 Amrit Science Campus, Tribhuvan University, Kathmandu 44613, Nepal; rajaram2620@gmail.com

2 Central Department of Chemistry, Tribhuvan University, Kirtipur Kathmandu 44613, Nepal; adk.laxmi@yahoo.com (L.A.); mandira43@hotmail.com (M.P.A.)

3 International Center for Materials Nanoarchitectonics (MANA), National Institute for Materials Science (NIMS), 1-1 Namiki, Ibaraki Tsukuba 305-0044, Japan; rekhashrestha3@hotmail.com (R.G.S.); ariga.katsuhiko@nims.go.jp (K.A.)

4 Department of Science and Humanities, Institute of Engineering, Tribhuvan University, Pulchowk Campus, Lalitpur 44700, Nepal; joshirinita@yahoo.com

* Correspondence: shrestha.lokkumar@nims.go.jp; Tel.: +81-29-860-4809

Academic Editor: Lidong Shao

Received: 7 April 2017; Accepted: 24 April 2017; Published: 26 April 2017

\begin{abstract}
In this paper, wool carpet dye adsorption properties of nanoporous activated carbon materials (NCMs) prepared from bamboo agro-product is reported. Bamboo cane powder was chemically activated with phosphoric acid at different temperatures $\left(400,500\right.$, and $\left.600{ }^{\circ} \mathrm{C}\right)$ at an impregnation ratio of 1:1. We found that the specific surface area and the total pore volume of NCM increases with temperature giving the highest surface area and pore volume ca. $2130 \mathrm{~m}^{2} \cdot \mathrm{g}^{-1}$ and $2.69 \mathrm{cc} \cdot \mathrm{g}^{-1}$ at $600{ }^{\circ} \mathrm{C}$. Owing to superior surface textural properties, bamboo-derived NCM showed excellent adsorption capacity for wool carpet dyes Lanasyn orange (LO) and Lanasyn gray (LG). The adsorption phenomena could be described by Langmuir/Freundlich adsorption isotherm models. The maximum adsorption capacity was ca. $2.60 \times 10^{3}$ and $3.04 \times 10^{3} \mathrm{mg} \cdot \mathrm{g}^{-1}$ for LO and LG, respectively. The adsorption followed pseudo second order kinetics with the second order rate constant of $1.24 \times 10^{-3} \mathrm{~g} \cdot \mathrm{mg}^{-1} \cdot \mathrm{min}^{-1}(\mathrm{LO})$ and $7.69 \times 10^{-4} \mathrm{~g} \cdot \mathrm{mg}^{-1} \cdot \mathrm{min}^{-1}(\mathrm{LG})$, respectively. This study demonstrated that the high surface area NCMs prepared from agro-product can be used as efficient and cost-effective adsorbent materials for the removal of dyes from industrial effluent.
\end{abstract}

Keywords: nanoporous carbon materials; wool carpet dyes; Lanasyn orange; Lanasyn gray; adsorption kinetics

\section{Introduction}

Nanoporous carbon materials (NCMs) have received considerable attention for their potential properties of adsorption of pollutants from an aqueous phase [1-5]. Industrial pollutants from textile and carpet dyeing industries possess intense color, so that the effluents from carpet dyeing industries not only change water color which is important for aesthetics, but also prevent light from penetrating through water, destroying the aquatic ecosystem and several aquatic species. This demonstrates the importance of efficient adsorbent materials for the removal of dyes from industrial effluents. NCMs, owing to their large surface area and well developed porosity, show excellent adsorption capacity for both neutral and charged pollutants including colorful dyes [6-10]. Adsorption phenomena depend both on the pore volume and surface area of NCMs. For instance, pore volume limits the size of molecules that can be adsorbed, and surface area determines the amount of material that 
can be adsorbed. Therefore, preparation of NCMs is crucial and, depending on the requirement or application, synthetic conditions need optimization. NCMs generally contain micropores (pore size below $2 \mathrm{~nm}$ ), mesopores $(2<$ pore size $<50 \mathrm{~nm}$ ) and macropores (pore size $>50 \mathrm{~nm}$ ) within their structures. The relative proportions of these pores vary considerably depending on the carbon source, activating agent and preparation conditions. NCM with large micro- and mesopores are suitable for the adsorption of pollutants from water [11-15].

NCMs can be prepared by physical or chemical activation of carbonaceous materials such as lignite, coal, peat, wood, etc. [16-20]. Physical activation requires rather high temperature $\left(800-1100{ }^{\circ} \mathrm{C}\right)$ treatment with a constant flow of steam, carbon dioxide, nitrogen or air [21]. While in chemical activation, the precursor material is mixed with certain dehydrating (activating) agents such as phosphoric acid $\left(\mathrm{H}_{3} \mathrm{PO}_{4}\right)$, potassium hydroxide $(\mathrm{KOH})$, sodium hydroxide $(\mathrm{NaOH})$, zinc chloride $\left(\mathrm{ZnCl}_{2}\right)$, sodium carbonate $\left(\mathrm{K}_{2} \mathrm{CO}_{3}\right)$, etc. Then, carbonization occurs at relatively lower temperatures compared to the physical activation temperature [22-26]. These activating agents induce important changes in the pyrolytic decomposition of the lignocellulosic materials promoting depolymerization and dehydration of constituent biopolymers. Chemical activation is preferential over physical activation for enhancing porosity at a low energy consumption. Maximum pores can be created by optimizing the synthetic conditions such as activation temperature, time, and proper selection of the activating agent and the impregnation ratio with a precursor $[27,28]$.

Despite the potential use of activated carbon in various fields, commercially available activated carbon is an expensive material for large-scale application. This demonstrates the necessity of a cost-effective method of producing high surface area and large porosity NCMs. Recently, various agro-wastes and agricultural products have been explored as low-cost precursors for the production of porous carbon materials. For instance, coconut shells, sugarcane bagasse, wood chips, sawdust, rice husks, corncobs, palm shells, lapsi seed stones, etc. have been regarded as potential precursors of high surface area NCMs [29-34]. Among various agricultural residues, the renewable natural bio-resource bamboo represents an important precursor material for the production of NCMs. Bamboo is the most diverse group of fastest growing plants in the grass family. It is widely used in Asia as scaffolding in construction and subsequently disposed as landfill waste. This bamboo waste can be utilized as a low-cost starting precursor material for the production of high surface area NCMs for large-scale industrial application. Note that use of sustainably derived NCMs from bio-masses or agro-waste could also be extended to other technological applications where more expensive carbon materials with limited availability such as graphene, carbon nanotube (CNT) and fullerenes are used for wastewater treatment.

In this contribution, we report the production of high surface area NCMs from low-cost agro-product bamboo cane by phosphoric activation and its wool carpet dye adsorption properties. Phosphoric acid-activation is considered over other common activating agents, as it causes the development of a hierarchical micro- and mesopore architecture in the carbon network, resulting in the formation of high surface area and large pore volume carbon materials [35]. The synthetic method includes the phosphoric acid-activation of bamboo cane powder at an impregnation ratio of 1:1. The effect of carbonization temperature on surface area, surface morphology, surface functional group, and structure was investigated. The prepared NCM was characterized by Fourier transform-infrared (FTIR) spectroscopy, Raman scattering, X-ray diffraction (XRD), scanning electron microscopy (SEM) and transmission electron microscopy (TEM). Surface area and pore volume were determined by nitrogen adsorption/desorption measurements. Bamboo-derived NCM showed excellent wool carpet dye (in the form of Lanasyn orange (LO) and Lanasyn gray (LG)) adsorption properties. The adsorption phenomena could be described by Langmuir and Freundlich adsorption isotherm models.

\section{Results and Discussion}

Surface morphology and porosity of the prepared NCMs were investigated by SEM and HR-TEM. Figure 1 shows typical SEM, TEM and HR-TEM images of the NCM_1_600. 

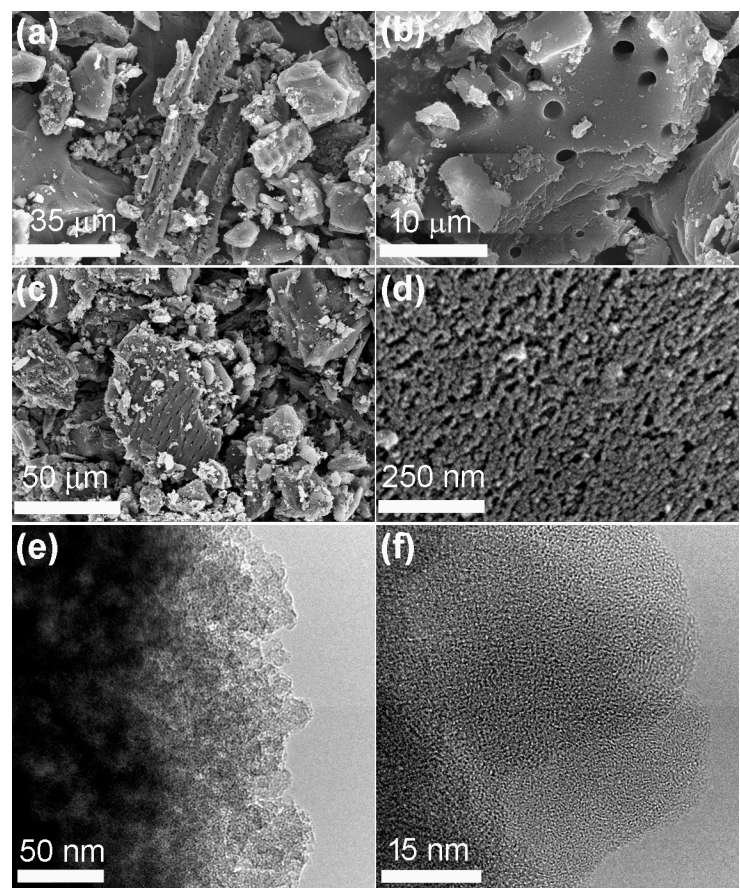

Figure 1. Electron microscopic images of NCM_1_600 as a typical example. (a-d) SEM; (e) TEM; and (f) HR-TEM images.

The SEM image reveals that NCM_1_600 contains fine granules (average size $~ 70 \mu \mathrm{m}$ ) having large number of macropores on the surface (Figure 1a-c). The homogeneous distribution of mesopores that can be seen in the high-resolution SEM (Figure 1d) and TEM image (Figure 1e) demonstrates the uniform carbonization/or activation of the bamboo cane precursor [30-33]. The HR-TEM image (Figure 1f) confirmed the amorphous structure of NCM_1_600, which is common to most activated carbons prepared from natural precursors. Similar surface morphology and pore structures were observed in NCM_1_500 and NCM_1_400 carbonized at 500 and $400{ }^{\circ} \mathrm{C}$, respectively.

FTIR spectra (Figure 2a) showed the presence of oxygen containing surface functional groups in the bamboo-derived NCMs.
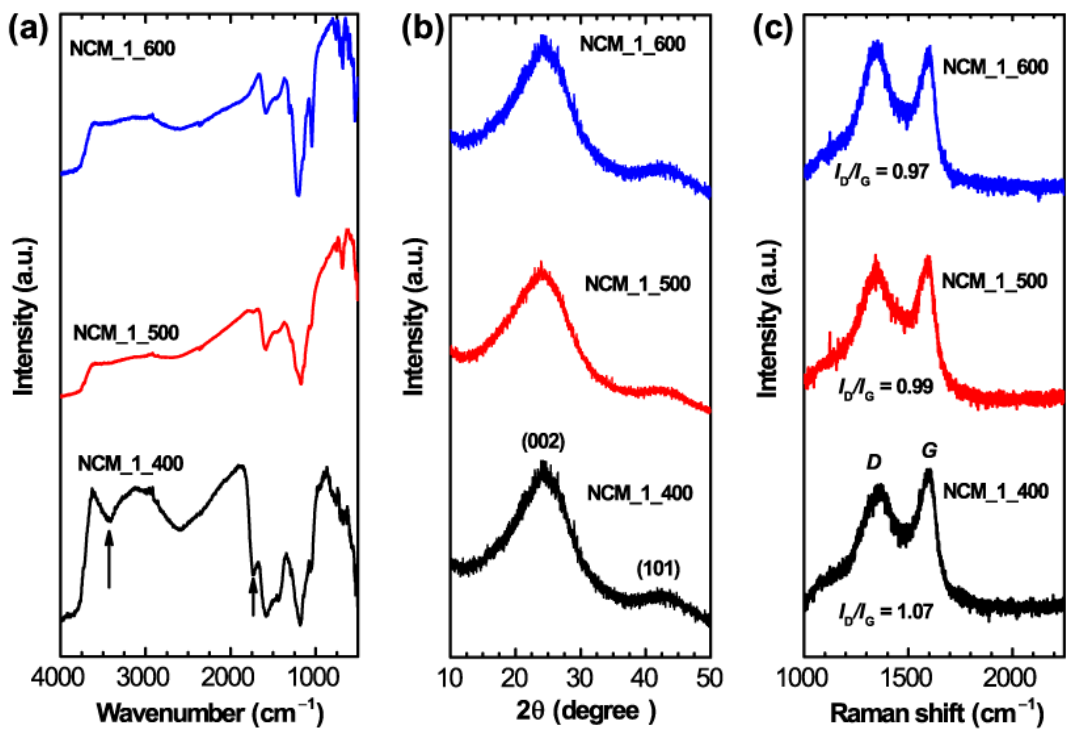

Figure 2. (a) FTIR spectra, (b) XRD patterns, and (c) Raman scattering spectra of NCM_1_400, NCM_1_500, and NCM_1_600. 
The FTIR band in the range of $3400-3500 \mathrm{~cm}^{-1}$ can be attributed to the $\mathrm{O}-\mathrm{H}$ stretching vibration of the hydroxyl functional groups. The band around $1700 \mathrm{~cm}^{-1}$ can be attributed to the stretching of the $\mathrm{C}=\mathrm{O}$ of the carboxylic acid group, and the band in the range of $1620-1660 \mathrm{~cm}^{-1}$ can be attributed to the skeletal $C=C$ stretching vibration in aromatic compounds. The FTIR band around $1000-1300 \mathrm{~cm}^{-1}$ corresponds to the stretching of the $\mathrm{C}-\mathrm{O}$ functional group, and the weak peaks in the range of $600-800 \mathrm{~cm}^{-1}$ correspond to aromatic $\mathrm{C}-\mathrm{H}$ bending. Note that the broad band at around $3400 \mathrm{~cm}^{-1}$ (corresponding to alcoholic or phenolic $-\mathrm{OH}$ stretching vibration) that was observed in the FTIR spectrum of NCM_1_400 is absent in the NCM_1_500 and NCM_1_600 samples, suggesting the decomposition of the carboxylic acid functional groups at higher carbonization temperatures of 500 and $600{ }^{\circ} \mathrm{C}$.

Two broad XRD peaks (Figure 2b) observed for NCM_1_x ( $x=400,500$, and 600) at diffraction angles near $2 \theta=25$ and 43 degrees are typical of amorphous carbons, and correspond to the (002) and (101) planes of micrographite clusters formed during the activation process [36,37]. The broad XRD peaks may also demonstrate that the graphitic clusters in the prepared NCM are rather small. As revealed by the HR-TEM image (Figure 1d), the ordered graphene layers are not fully developed due to the lower activation temperature. Sharp XRD peak followed by ordered graphitic layers can be observed upon heating carbon precursors at a very high temperature of $2000{ }^{\circ} \mathrm{C}$ [38]. Raman scattering technique is used to study the graphitization degree, defects and bonding states of the prepared carbon material [38-40]. The recorded Raman scattering spectra of NCM_1_x ( $x=400,500$, and 600) contain two broad bands approximately at $1350(D)$ and $1597 \mathrm{~cm}^{-1}(G)$ (Figure 2c), again typical of amorphous carbons [41]. The defect-induced $D$ band is caused by the disordered structure of graphene and corresponds to $s p^{3}$ carbon, while the graphitic $G$ band is due to the $E_{2 \mathrm{~g}}$ mode and arises from the $\mathrm{C}-\mathrm{C}$ bond stretching in graphitic materials. The $G$ band is common to all $s p^{2}$ carbon systems. The degree of graphitization estimated by the relative intensity of the $G$ and $D$ bands $\left(I_{\mathrm{G}} / I_{\mathrm{D}}\right)$ seems to be apparently unchanged upon increasing the carbonization temperature from 400 to $600{ }^{\circ} \mathrm{C}$. The $I_{\mathrm{G}} / I_{\mathrm{D}}$ is found in the range of 1.07 to 0.97 , demonstrating partially graphitized carbons (Figure 2c).

Nitrogen adsorption-desorption measurements were carried out to determine the Brunauer-Emmett-Teller (BET) surface area and pore volume of the prepared NCMs. Figure 3 shows adsorption isotherms and the corresponding pore size distributions obtained by Barrett-Joyner-Halenda (BJH) and density functional theory (DFT). Adsorption isotherms revealed that nitrogen uptake strongly depends on the temperature, indicating that the carbonization temperature plays an important role on the surface textural properties such as surface area and pore volume of NCMs. The prepared NCMs displayed mixed Type-I/Type-IV adsorption isotherms [42,43]. Nitrogen uptake increases considerably at lower relative pressure, with a hysteresis loop observed at higher relative pressures (Figure 3a), which is a typical isotherm of porous materials containing both micro- and mesopore structures. Large nitrogen uptake at lower relative pressure is a well-known phenomenon of micropore filling, while the hysteresis loop is caused by capillary condensation occurring in the mesopores. From adsorption isotherms, BET surface areas are ca. $1431 \mathrm{~m}^{2} \cdot \mathrm{g}^{-1}$ (NCM_1_400), $1340 \mathrm{~m}^{2} \cdot \mathrm{g}^{-1}$ (NCM_1_500), and $2129 \mathrm{~m}^{2} \cdot \mathrm{g}^{-1}$ (NCM_1_600). Note that the observed BET surface area of $2129 \mathrm{~m}^{2} \cdot \mathrm{g}^{-1}$ is higher than that of commercially available activated carbon, whose surface area is found to be approximately $1000-1200 \mathrm{~m}^{2} \cdot \mathrm{g}^{-1}[42,43]$. Total pore volumes of the prepared NCMs are ca. $1.10 \mathrm{~cm}^{3} \cdot \mathrm{g}^{-1}$ (NCM_1_400), $2.01 \mathrm{~cm}^{3} \cdot \mathrm{g}^{-1}$ (NCM_1_500), and $2.69 \mathrm{~cm}^{3} \cdot \mathrm{g}^{-1}$ (NCM_1_600). 

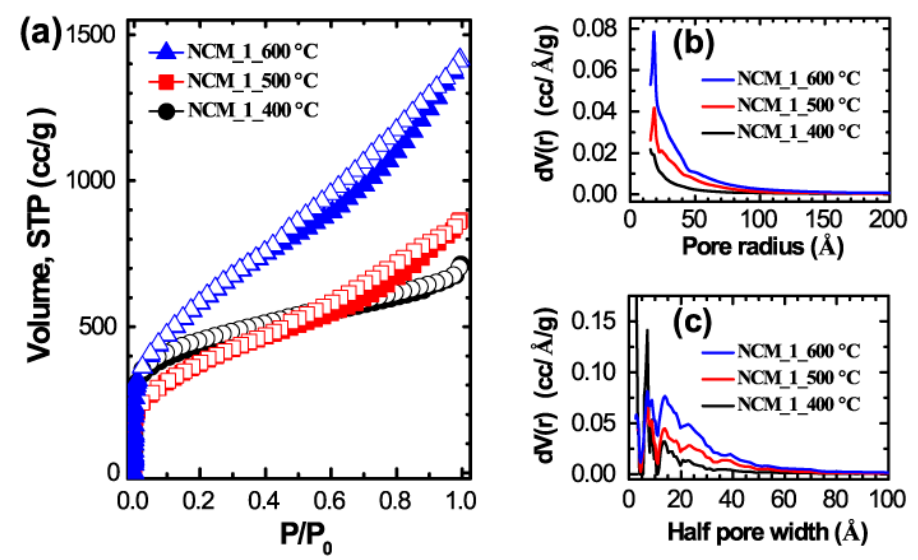

Figure 3. (a) Nitrogen adsorption-desorption isotherms of NCM_1_x ( $x=400,500$, and 600); (b) Pore size distribution curves obtained from BJH method; and (c) corresponding pore size distribution curves obtained from DFT method.

High surface area activated carbons have been used as efficient adsorbents for the removal of organic dyes from water [44-50]. Inspired by the observed high surface area $\left(2129 \mathrm{~m}^{2} \cdot \mathrm{g}^{-1}\right)$ and large pore volume $\left(2.69 \mathrm{~cm}^{3} \cdot \mathrm{g}^{-1}\right)$, we investigated the adsorption properties of wool carpet dyes (LO and LG) on NCM_1_600. The UV/Vis absorption spectra of LO and LG were recorded, and $\lambda_{\max }$ for LO and LG were estimated to 475 and $560 \mathrm{~nm}$, respectively. The concentration of these dyes for absorption and kinetic studies were determined by measuring the absorbance at their respective $\lambda_{\max }$. Figure 4 a shows the plots of $C_{e} / q_{e}$ versus $C_{e}$ for the adsorption of LO and LG onto NCM_1_600 according to the linearized Langmuir isotherm equation.

The observed good correlation coefficient implies the homogeneous monolayer coverage of the dye molecule on the surface of the adsorbent. The maximum adsorption capacity, $q_{m}$ for the adsorption of LO and LG were found to be $2.60 \times 10^{3} \mathrm{mg} \cdot \mathrm{g}^{-1}$ and $3.04 \times 10^{3} \mathrm{mg} \cdot \mathrm{g}^{-1}$, respectively. The observed high adsorption capacity of NCM_1_600 can be attributed to the high surface area and large pore volume of the bamboo-derived nanoporous carbons. The $R_{L}$ value for $L O$ and LG were ca. $4.3 \times 10^{-4}$ and $7.3 \times 10^{-3}$, respectively, which indicates that NCM_1_600 is a favorable adsorbent for the adsorption of LO and LG wool carpet dyes.

We also tested the Freundlich adsorption model. Figure $4 \mathrm{~b}$ shows the plot of $\log q_{e}$ against $\log C_{e}$ for the adsorption of LO and LG onto NCM_1_600, according to the linearized Freundlich isotherm equation. The Langmuir and Freundlich adsorption parameters are summarized in Table 1. The correlation coefficients for the Freundlich plot is higher than that for the Langmuir plot, which indicates that the adsorption of wool carpet dyes can better be described by the Freundlich adsorption isotherms.
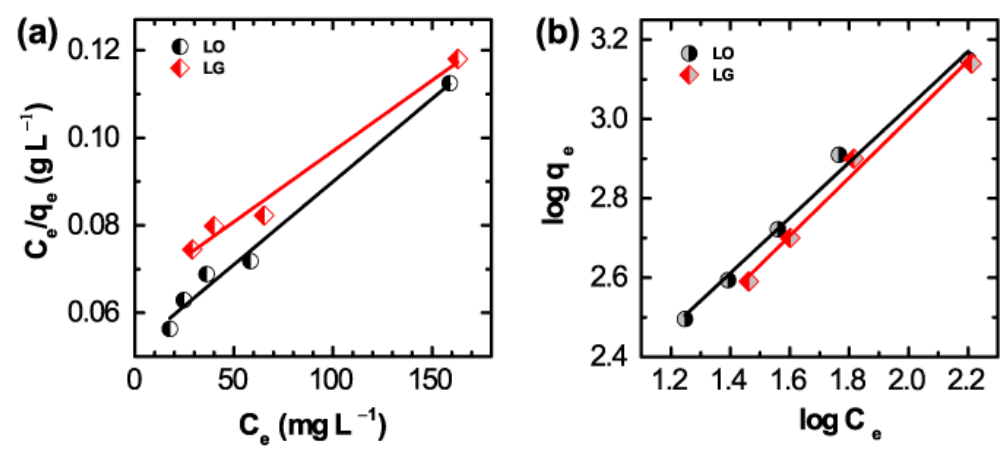

Figure 4. (a) Langmuir adsorption isotherms and (b) Freundlich adsorption isotherms for LO and LG on NCM_1_600. 
Table 1. Langmuir and Freundlich adsorption parameters for LO and LG.

\begin{tabular}{ccc}
\hline Parameters & LO & LG \\
\hline$q_{m}\left(\mathrm{mg} \cdot \mathrm{g}^{-1}\right)$ & $2.60 \times 10^{3}$ & $3.04 \times 10^{3}$ \\
$K_{L}\left(\mathrm{~L} \mathrm{mg}^{-1}\right)$ & 7.83 & 4.59 \\
$R_{L}$ & $4.3 \times 10^{-4}$ & $7.3 \times 10^{-3}$ \\
$R^{2}$ & 0.9841 & 0.976 \\
$1 / \mathrm{n}$ & 0.6986 & 0.7651 \\
$\mathrm{n}$ & 1.43 & 1.31 \\
$K_{F}\left(\mathrm{mg}^{-} \mathrm{g}^{-1}\right)$ & 42.93 & 29.54 \\
$R^{2}$ & 0.9908 & 0.9899 \\
\hline
\end{tabular}

Pseudo first order (Figure 5a) and pseudo second order (Figure 5b) kinetics models were tested for the adsorption of LO and LG dyes.
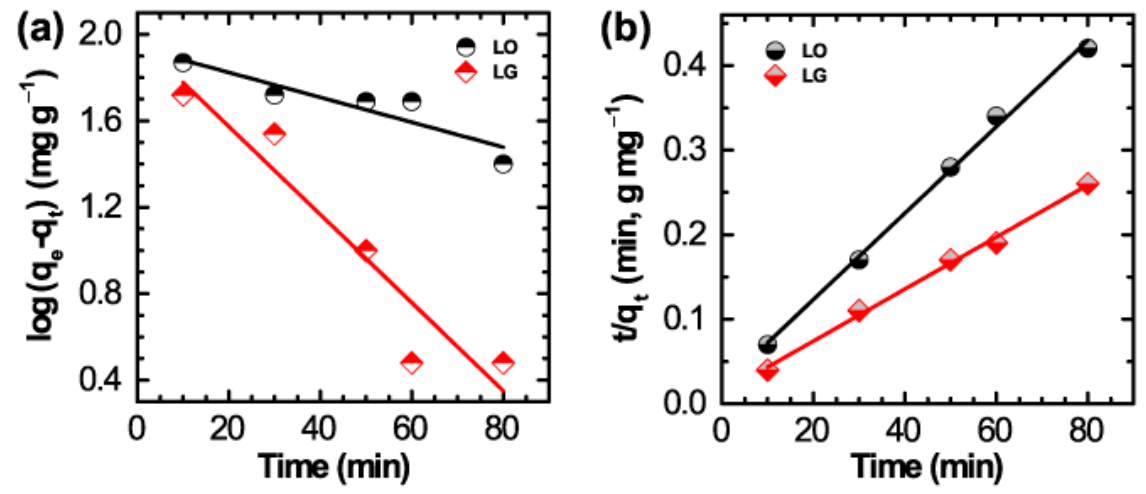

Figure 5. Adsorption kinetics of LO and LG adsorption on NCM_1_600. (a) Pseudo first order and (b) pseudo second order models.

The correlation coefficient for the pseudo second order kinetics for both the dyes were found to be better than that of the pseudo first order kinetics, demonstrating that the adsorption process follows the second order kinetics model. Different kinetic parameters for both pseudo first and pseudo second order kinetics are summarized in Table 2. Judging from the kinetic parameters, we concluded that the adsorption of LO and LG dyes on NCM_1_600 follows the pseudo second order kinetics model.

Table 2. Kinetic parameters for pseudo first and pseudo second order reactions for the adsorption of LO and LG dyes on NCM_1_600.

\begin{tabular}{ccc}
\hline Dye & Pseudo 1st Order & Pseudo 2nd Order \\
\hline & $k_{1}=1.36 \times 10^{-3} \mathrm{~L} \cdot \mathrm{min}^{-1}$ & $k_{2}=1.24 \times 10^{-3} \mathrm{~g} \cdot \mathrm{mg}^{-1} \cdot \mathrm{min}^{-1}$ \\
LO & $q_{e}=86.98 \mathrm{mg} \cdot \mathrm{g}^{-1}$ & $q_{e}=196.1 \mathrm{mg} \cdot \mathrm{g}^{-1}$ \\
& $R^{2}=0.8648$ & $R^{2}=0.9963$ \\
\hline & $k_{1}=4.70 \times 10^{-2} \mathrm{~L} \cdot \mathrm{min}^{-1}$ & $k_{2}=7.69 \times 10^{-4} \mathrm{~g} \cdot \mathrm{mg}^{-1} \cdot \mathrm{min}^{-1}$ \\
LG & $q_{e}=95.85 \mathrm{mg} \cdot \mathrm{g}^{-1}$ & $q_{e}=323 \mathrm{mg} \cdot \mathrm{g}^{-1}$ \\
& $R^{2}=0.9046$ & $R^{2}=0.9963$ \\
\hline
\end{tabular}

\section{Materials and Methods}

\subsection{Materials}

Agro-product bamboo cane was collected from the local forest. Orthophosphoric acid $\left(\mathrm{H}_{3} \mathrm{PO}_{4}\right)$ $88 \%(w / w)$ was the product of Tokyo Chemical Industries, Tokyo, Japan, and was used as received. Millipore filter water was used to prepare solutions. 


\subsection{Preparation of Nanoporous Carbon Material (NCM)}

Bamboo cane was washed with distilled water and dried in an oven at $120^{\circ} \mathrm{C}$ for $24 \mathrm{~h}$. The dried bamboo cane was then cut into small pieces, ground in an electric grinder and sieved through a sieve of $250 \mu \mathrm{m}$. Bamboo cane powder was mixed with the requisite amount of phosphoric acid in the ratio of $1: 1$ and the mixture was stored at $25{ }^{\circ} \mathrm{C}$ for $24 \mathrm{~h}$ and dried in an oven at $120{ }^{\circ} \mathrm{C}$ for $12 \mathrm{~h}$. Carbonization was then performed in a tubular furnace (21100, Tube Furnace, Thermolyne, IA, USA) at 400,500 and $600{ }^{\circ} \mathrm{C}$ under a continuous flow of water vapor-saturated nitrogen gas for $2 \mathrm{~h}$ at the flow rate of $100 \mathrm{~mL} \cdot \mathrm{min}^{-1}$. The carbonized products were washed with Millipore filter water until the solution $\mathrm{pH}$ reached $\sim 7$. The obtained product was dried at $110^{\circ} \mathrm{C}$ for $6 \mathrm{~h}$ and referred to as NCM_1_x, where $x=400,500$, and 600, and represents the carbonization temperature.

\subsection{Characterizations}

Surface functional groups of NCM_1_ $x(x=400,500$ and 600) were determined by recording FTIR spectra on Thermo Electron Corporation (Walthan, MA, USA), Nicolet 4700 at $25^{\circ} \mathrm{C}$. For the structural analysis, X-ray diffraction (XRD) patterns were recorded on an Rigaku X-Ray diffractometer, RINT, Japan, operated at $40 \mathrm{kV}$ and $40 \mathrm{~mA}$ with $\mathrm{Cu}-\mathrm{K}_{\alpha}$ radiation at $25^{\circ} \mathrm{C}$. For the bonding state and types of carbon, Raman Scattering spectra were recorded on a Jobin-Yvon T64000 using green laser of $514.5 \mathrm{~nm}$ and $0.5 \mathrm{~mW}$ power. Surface morphology was studied by taking SEM images on a U-8000, Hitachi Co. Ltd. (Tokyo, Japan), operated at $10 \mathrm{kV}$ and $10 \mu \mathrm{A}$. Microstructure and porosity were also studied by TEM. High resolution TEM (HR-TEM) images were taken on a JEOL JEM-2100F at an operating voltage of $200 \mathrm{KV}$. Surface textural properties (Brunauer-Emmett-Teller (BET) surface areas, total pore volume and average pore diameter) were investigated by recording $\mathrm{N}_{2}$ adsorption-desorption isotherms on an automatic adsorption instrument (Quantachrome Instrument, Autosorb-1, Boynton Beach, FL, USA).

\subsection{Adsorption of Wool Carpet Dyes}

Adsorption properties of wool carpet dyes Lanasyn orange (LO) and Lanasyn gray (LG) on NCM_1_600 were studied. For recording adsorption isotherms, NCM_1_600 (5 to $45 \mathrm{mg}$ ) was placed in five reagent bottles, and dye solution ( $50 \mathrm{~mL}: 300 \mathrm{ppm}$ ) was added and equilibrated by shaking in a rotary electric shaker for $\sim 24 \mathrm{~h}$. The solutions were centrifuged and filtered. Concentrations of dyes in the filtrates were determined spectrophotometrically by measuring the absorbance at 475 and $560 \mathrm{~nm}$, corresponding to $\lambda_{\max }$ for LO and LG, respectively. The adsorption isotherms were analyzed using Langmuir and Freundlich adsorption models. The linearized form of the Langmuir adsorption isotherm can be described as:

$$
\frac{C_{e}}{q_{e}}=\frac{1}{q_{m} K_{L}}+\left(\frac{1}{q_{m}}\right) C_{e}
$$

where $C_{e}=$ equilibrium concentration of solution in $\mathrm{mg} \cdot \mathrm{L}^{-1}, q_{e}=$ amount of adsorbate adsorbed by $1 \mathrm{~g}$ of adsorbent, $q_{m}=$ maximum amount of adsorbate $(\mathrm{mg})$ adsorbed by $1 \mathrm{~g}$ of adsorbent $\left(\mathrm{mg} \cdot \mathrm{g}^{-1}\right)$, and $K_{L}$ represents the Langmuir adsorption constant $\left(\mathrm{L} \cdot \mathrm{mg}^{-1}\right)$. Langmuir constants relate the adsorption capacity of the adsorbate on the adsorbent.

The applicability of the Langmuir isotherm is sometime expressed in terms of dimensionless separation factor $R_{L}$, defined as:

$$
R_{L}=\frac{1}{1+K_{L} C_{0}}
$$

where, $K_{L}$ is the Langmuir constant and $C_{0}$ the highest dye concentration $\left(\mathrm{mg} \cdot \mathrm{L}^{-1}\right)$. The value of $R_{L}$ indicates the type of adsorption to be either unfavorable $\left(R_{L}>1\right)$, linear $\left(R_{L}=1\right)$, favorable $\left(0<R_{L}<1\right)$, or reversible $(=0)$.

The linearized form of the Freundlich adsorption isotherm can be expressed as:

$$
\log q_{e}=\log K_{F}+\left(\frac{1}{n}\right) \log C_{e}
$$


where $q_{e}=x / m, x=$ the mass of substance $(\mathrm{mg})$ adsorbed, $\mathrm{m}=$ the mass of adsorbent $(\mathrm{g})$, and $K_{F}$ and $n$ are Freundlich adsorption parameters, with $n$ indicating adsorption intensity, and $K_{F}\left(\mathrm{mg} \cdot \mathrm{g}^{-1}\right)$ the adsorption capacity of the adsorbent.

The rate and mechanism of the adsorption process may be determined by kinetic studies. Dye adsorption on the adsorbent were analyzed by pseudo first order and pseudo second order models. The pseudo first order equation is given by Langergren and Svenska:

$$
\ln \left(q_{e}-q_{t}\right)=\ln q_{e}-k_{1} t
$$

where $q_{e}$ and $q_{t}$ are the amount of dye adsorbed $\left(\mathrm{mg} \cdot \mathrm{g}^{-1}\right)$ at equilibrium and at time $t$, respectively, and $\mathrm{k}_{1}$ is the rate constant for adsorption. The values of rate constants were evaluated from the plots of $\log \left(q_{e}-q_{t}\right)$ versus $t$.

The pseudo second order equation is given by Ho:

$$
\frac{t}{q_{t}}=\frac{1}{k_{2} q_{e}^{2}}+\left(\frac{1}{q_{e}}\right) t
$$

If the adsorption process follows pseudo second order kinetics, the plot of $t / q_{t}$ against $t$ should be linear, and can be evaluated with the slope and intercept equal to $q_{e}$ and $k_{2}$.

\section{Conclusions}

High surface area nanoporous carbons materials (NCMs) have been prepared by the chemical activation of bamboo powder with phosphoric acid-activation at different temperatures $\left(400-600{ }^{\circ} \mathrm{C}\right)$. The surface area and pore volume of $\mathrm{NCM}$ at $600{ }^{\circ} \mathrm{C}$ were ca. $2130 \mathrm{~m}^{2} \cdot \mathrm{g}^{-1}$ and $2.69 \mathrm{cc} \cdot \mathrm{g}^{-1}$, respectively. Owing to the high surface area and large pore volume, the bamboo-derived NCM showed excellent adsorption capacity for the wool carpet dyes Lanasyn orange (LO) and Lanasyn gray (LG). The Langmuir adsorption isotherm model explained the adsorption phenomena, giving maximum adsorption capacity at ca. $2.60 \times 10^{3} \mathrm{mg} \cdot \mathrm{g}^{-1}$ (LO) and $3.04 \times 10^{3} \mathrm{mg} \cdot \mathrm{g}^{-1}$ (LG), respectively. The adsorption followed the pseudo second order kinetics model with the second order rate constant of $1.24 \times 10^{-3} \mathrm{~g} \cdot \mathrm{mg}^{-1} \cdot \mathrm{min}^{-1}$ (LO) and $7.69 \times 10^{-4} \mathrm{~g} \cdot \mathrm{mg}^{-1} \cdot \mathrm{min}^{-1}$ (LG), respectively. This study demonstrated that high surface area NCMs prepared from agro-products could be potential cost-effective and efficient adsorbent materials for the removal of dyes from industrial effluent.

Acknowledgments: This work is partly supported by the World Premier International Research Initiative (WPI Initiative), Ministry of Education, Culture, Sports, Science and Technology (MEXT), Japan. Laxmi Adhikari thanks the International Center for Materials Nanoarchitectonics (WPI-MANA) and National Institute for Materials Science (NIMS) for the internship award.

Author Contributions: Raja Ram Pradhananga and Lok Kumar Shrestha conceived and designed the experiments; Laxmi Adhikari and Rekha Goswami Shrestha performed the experiments; Mandira Pradhananga Adhikari, Rinita Rajbhandari, Raja Ram Pradhananga analyzed the data; Lok Kumar Shrestha and Rekha Goswami Shrestha contributed reagents/materials/analysis tools; Lok Kumar Shrestha, Raja Ram Pradhananga and Katsuhiko Ariga discussed the data and wrote the paper.

Conflicts of Interest: The authors declare no conflict of interest.

\section{References}

1. Peláez-Cid, A.-A.; Herra-González, A.-M.; Salazar-Villanueva, M.; Bautista-Hernández, A. Elimination of textile dyes using activated carbons prepared from vegetable residues and their characterization. J. Environ. Manag. 2017, 181, 269-278. [CrossRef] [PubMed]

2. Hassan, A.F.; Elhadidy, H. Production of activated carbons from waste carpets and its application in methylene blue adsorption: Kinetic and thermodynamic study. J. Environ. Chem. Eng. 2017, 5, 955-963. [CrossRef] 
3. Dong, P.; Maneerung, T.; Ng, W.C.; Zhen, X.; Dai, Y.; Tong, Y.W.; Ting, Y.-P.; Koh, S.N.; Wang, C.-H.; Neoh, K.G. Chemically treated carbon black waste and its potential applications. J. Hazard. Mater. 2017, 321, 62-72. [CrossRef] [PubMed]

4. Yu, M.; Li, J.; Wang, L. KOH-activated carbon aerogels derived from sodium carboxymethyl cellulose for high-performance supercapacitors and dye adsorption. Chem. Eng. J. 2017, 310, 300-306. [CrossRef]

5. Wei, M.; Gao, L.; Li, J.; Fang, J.; Cai, W.; Li, X.; Xu, A. Activation of peroxymonosulfate by graphitic carbon nitride loaded on activated carbon for organic pollutants degradation. J. Hazard. Mater. 2016, 316, 60-68. [CrossRef] [PubMed]

6. Silva, T.L.; Ronix, A.; Pezoti, O.; Souza, L.S.; Leandro, P.K.T.; Bedin, K.C.; Beltrame, K.K.; Cazetta, A.L.; Almeida, V.C. Mesoporous activated carbon from industrial laundry sewage sludge: Adsorption studies of reactive dye removal Brilliant Blue R. Chem. Eng. J. 2016, 303, 467-476. [CrossRef]

7. Chen, J.; Zhang, L.; Huang, T.; Li, W.; Wang, Y.; Wang, Z. Decolorization of azo dye by peroxymonosulfate activated by carbon nanotube: Radical versus non-radical mechanism. J. Hazard. Mater. 2016, 320, 571-580. [CrossRef] [PubMed]

8. Njoku, V.O.; Foo, K.Y.; Asif, M.; Hameed, B.H. Preparation of activated carbons from rambutan (Nephelium lappaceum) peel by microwave-induced $\mathrm{KOH}$ activation for acid yellow 17 dye adsorption. Chem. Eng. J. 2014, 250, 198-204. [CrossRef]

9. Jain, A.; Balasubramanian, R.; Srinivasan, M.P. Production of high surface area mesoporous activated carbons from waste biomass using hydrogen peroxide-mediated hydrothermal treatment for adsorption applications. Chem. Eng. J. 2015, 273, 622-629. [CrossRef]

10. Ahmed, M.J. Application of agricultural based activated carbons by microwave and conventional activations for basic dye adsorption: Review. J. Environ. Chem. Eng. 2016, 4, 89-99. [CrossRef]

11. Bunmahotama, W.; Hung, W.-N.; Lin, T.-F. Prediction of the adsorption capacities of four typical pollutants on activated carbons in natural waters. Water Res. 2017, 111, 28-40. [CrossRef] [PubMed]

12. Yagmur, E.; Turkoglu, S.; Banford, A.; Aktas, Z. The relative performance of microwave regenerated activated carbons on the removal of phenolic pollutants. J. Clean. Prod. 2017, 149, 1109-1117. [CrossRef]

13. Machida, M.; Chensun, S.; Amano, Y.; Iamzeki, F. Adsorptive removal of $\mathrm{Pb}(\mathrm{II})$ ions from aqueous solution by $\left(\mathrm{NH}_{4}\right)_{2} \mathrm{~S}_{2} \mathrm{O}_{8}$ oxidized activated carbons. Bull. Chem. Soc. Jpn. 2015, 88, 127-132. [CrossRef]

14. Giannakoudakis, D.A.; Kyzas, G.Z.; Avranas, A.; Lazaridis, N.K. Multi-parametric adsorption effects of the reactive dye removal with commercial activated carbons. J. Mol. Liq. 2016, 213, 381-389. [CrossRef]

15. Spagnoli, A.A.; Giannakoudakis, D.A.; Bashkova, S. Adsorption of methylene blue on cashew nut shell based carbons activated with zinc chloride: The role of surface and structural parameters. J. Mol. Liq. 2017, 229, 465-471. [CrossRef]

16. Tong, K.; Lin, A.; Ji, G.; Wang, D.; Wang, X. The effects of adsorbing organic pollutants from super heavy oil wastewater by lignite activated coke. J. Hazard. Mater. 2016, 308, 113-119. [CrossRef] [PubMed]

17. Hadi, P.; Yeung, K.Y.; Guo, J.; Wang, H.; Mckey, G. Sustainable development of tyre char-based activated carbons with different textural properties for value-added applications. J. Environ. Manag. 2016, 170, 1-7. [CrossRef] [PubMed]

18. Thue, P.S.; Adebayo, M.A.; Lima, E.C.; Sieliechi, J.M.; Machado, F.M.; Dotto, G.L.; Vaghetti, J.C.P.; Dias, S.L.P. Preparation, characterization and application of microwave-assisted activated carbons from wood chips for removal of phenol from aqueous solution. J. Mol. Liq. 2016, 223, 1067-1080. [CrossRef]

19. Donald, J.; Ohtsuka, Y.; Xu, C.C. Effects of activation agents and intrinsic minerals on development in activated carbons derived from a Canadian peat. Mater. Lett. 2011, 65, 744-747. [CrossRef]

20. Foo, K.Y.; Hameed, B.H. Mesoporous activated carbon from wood sawdust by $\mathrm{K}_{2} \mathrm{CO}_{3}$ activation using microwave heating. Bioresour. Technol. 2012, 111, 425-432. [CrossRef] [PubMed]

21. González, J.F.; Román, S.; González-García, C.M.; Nabais, J.M.V.; Ortiz, A.L. Porosity development in activated carbons prepard from walnut shells by carbon dioxide or steam activation. Ind. Eng. Chem. Res. 2009, 48, 7474-7481. [CrossRef]

22. Elmouwahidi, A.; Bailón-García, E.; Pérez-Cadenas, A.F.; Maldonado-Hódar, F.J.; Carrasco-Marín, F. Activated carbons from $\mathrm{KOH}$ and $\mathrm{H}_{3} \mathrm{PO}_{4}$-activation of olive residues and its application as supercapacitor electrodes. Electrochim. Acta 2017, 229, 219-228. [CrossRef] 
23. Cazetta, A.L.; Vargas, A.M.M.; Nogami, E.M.; Kunita, M.H.; Guilherme, M.R.; Martins, A.C.; Silva, T.L.; Moraes, J.C.G.; Almeida, V.V. NaOH-activated carbon of high surface area produced from coconut shell: Kinetics and equilibrium studies from the methylene blue adsorption. Chem. Eng. J. 2011, 174, 117-125. [CrossRef]

24. Rajbhandari, R.; Shrestha, L.K.; Pradhananga, R.R. Nanoporous activated carbon derived from Lapsi (Choerospondias Axillaris) seed stone for the removal of arsenic from water. J. Nanosci. Nanotechnol. 2012, 12, 7002-7009. [CrossRef] [PubMed]

25. Okman, I.; Karagöz, S.; Tay, T.; Erdem, M. Activated carbon from grape seeds by chemical activation with potassium carbonate and potassium hydroxide. Appl. Surf. Sci. 2014, 293, 138-142. [CrossRef]

26. Hayashi, J.; Horikawa, T.; Takeda, I.; Muroyama, K.; Nasir-Ani, F. Preparing activated carbons from various nutshells by chemical activation with $\mathrm{K}_{2} \mathrm{CO}_{3}$. Carbon 2002, 40, 2381-2386. [CrossRef]

27. Rafatullaha, M.; Sulaimana, O.; Hashima, R.; Ahmad, A. Adsorption of methylene blue on low-cost adsorbents: A review. J. Hazard. Mater. 2010, 177, 70-80. [CrossRef] [PubMed]

28. Hameed, B.H. Evaluation of papaya seeds as a novel non-conventional low-cost adsorbent for removal of methylene blue. J. Hazard. Mater. 2009, 162, 939-944. [CrossRef] [PubMed]

29. Yuen, F.K.; Hameed, B.H. Recent developments in the preparation and regeneration of activated carbons my microwaves. Adv. Colloid Interface Sci. 2009, 149, 19-27. [CrossRef] [PubMed]

30. Zhang, S.; Zheng, M.; Lin, Z.; Li, N.; Liu, Y.; Zhao, B.; Pang, H.; Cao, J.; He, P.; Shi, Y. Activated carbon with ultrahigh specific surface area synthesized from natural plant material for lithium-sulfur batteries. J. Mater. Chem. A 2014, 2, 15889-15896. [CrossRef]

31. Shrestha, L.K.; Adhikari, L.; Shrestha, R.G.; Adhikari, M.P.; Adhikari, R.; Hill, J.P.; Pradhananga, R.R.; Ariga, K. Nanoporous carbon materials with enhanced supercapacitance performance and non-aromatic chemical sensing with $C_{1} / C_{2}$ alcohol discrimination. Sci. Technol. Adv. Mater. 2016, 17, 483-492. [CrossRef] [PubMed]

32. Adhikari, M.P.; Adhikari, R.; Shrestha, R.G.; Rajendran, R.; Adhikari, L.; Bairi, P.; Pradhananga, R.R.; Shrestha, L.K.; Ariga, K. Nanoporous activated carbon derived from agro-waste corncob for enhanced electrochemical and sensing performance. Bull. Chem. Soc. Jpn. 2015, 88, 1108-1115. [CrossRef]

33. Joshi, S.; Shrestha, L.K.; Kamachi, Y.; Malgras, V.; Pradhananga, M.A.; Pokharel, B.P.; Naata, T.; Pradhananga, R.R.; Ariga, K.; Yamauchi, Y. Synthesis and characterizations of nanoporous carbon derived from Lapsi (Choerospondias axillaris) seed: Effect of carbonization conditions. Adv. Powder Technol. 2015, 26, 894-900. [CrossRef]

34. Joshi, S.; Shrestha, L.K.; Kamachi, Y.; Yamauchi, Y.; Pradhananga, M.A.; Pokhrel, B.P.; Ariga, K.; Pradhananga, R.R. Sodium hydroxide activated nanoporous carbons based on Lapsi seed stone. J. Nanosci. Nanotechnol. 2015, 15, 1465-1472. [CrossRef] [PubMed]

35. Shrestha, L.K.; Shrestha, R.G.; Joshi, S.; Rajbhandari, R.; Shrestha, N.; Adhikari, M.P.; Pradhananga, R.R.; Ariga, K. Nanoarchitectonics of nanoporous carbon materials from natural resource for supercapacitor application. J. Inorg. Organomet. Polym. 2017. [CrossRef]

36. Zhu, Z.; Li, A.; Yan, L.; Liu, F.; Zhang, Q. Preparation and characterization of highly mesoporous spherical activated carbons from divinylbenzene-derived polymer by $\mathrm{ZnCl}_{2}$ activation. J. Colloid Interface Sci. 2007, 316, 628-634. [CrossRef] [PubMed]

37. Li, Z.Q.; Lu, C.J.; Xia, Z.P.; Zhou, Y.; Luo, Z. X-ray diffraction patterns of graphite and turbostratic carbon. Carbon 2007, 45, 1686-1695. [CrossRef]

38. Shrestha, L.K.; Shrestha, R.G.; Yamauchi, Y.; Hill, J.P.; Nishimura, T.; Miyazawa, K.; Kawai, T.; Okada, S.; Wakabayashi, K.; Ariga, K. Nanoporous carbon tubes from fullerene crystal as the $\pi$-electron carbon source. Angew. Chem. Int. Ed. 2015, 54, 951-955. [CrossRef] [PubMed]

39. Bairi, P.; Shrestha, R.G.; Hill, J.P.; Nishimura, T.; Ariga, K.; Shrestha, L.K. Mesoporous graphitic carbon microtubes derived from fullerene $C_{70}$ tubes as a high performance electrode material for advanced supercapacitors. J. Mater. Chem. A 2016, 4, 13899-13906. [CrossRef]

40. Shrestha, L.K.; Shrestha, R.G.; Hill, J.P.; Tsuruoka, T.; Ji, Q.; Nishimura, T.; Ariga, K. Surfactant-Triggered Nanoarchitectonics of Fullerene $C_{60}$ Crystals at a Liquid-Liquid Interface. Langmuir 2016, 32, 12511-12519. [PubMed]

41. Ferrari, A.C.; Robertson, J. Interpretation of Raman spectra of disordered and amorphous carbon. Phys. Rev. B 2000, 61, 14095-14107. [CrossRef] 
42. Ma, T.-Y.; Liu, L.; Yuan, Z.-Y. Direct synthesis of ordered mesoporous carbons. Chem. Soc. Rev. 2013, 42, 3977-4003. [CrossRef] [PubMed]

43. Lee, J.; Kim, J.; Hyeon, T. Recent progress in the synthesis of porous carbon materials. Adv. Mater. 2006, 18, 2073-2094. [CrossRef]

44. Foo, K.Y.; Hameed, B.H. Dynamic adsorption behavior of methylene blue onto oil palm shell granular activated carbon prepared by microwave heating. Chem. Eng. J. 2012, 203, 81-87. [CrossRef]

45. Hameeda, B.H.; El-Khaiary, M.I. Removal of basic dye from aqueous medium using a novel agricultural waste material: Pumpkin seed hull. J. Hazard. Mater. 2008, 155, 601-609. [CrossRef] [PubMed]

46. Qada, E.N.E.; Allen, S.J.; Walker, G.M. Adsorption of basic dyes from aqueous solution onto activated carbons. Chem. Eng. J. 2008, 135, 174-184. [CrossRef]

47. Rodríguez, A.; García, J.; Ovejero, G.; Mestanza, M. Adsorption of anionic and cationic dyes on activated carbon from aqueous solutions: Equilibrium and kinetics. J. Hazard. Mater. 2009, 172, 1311-1320. [CrossRef] [PubMed]

48. Liu, Q.S.; Zheng, T.; Wang, N.L.P.; Abulikemu, G. Modification of bamboo-based activated carbon using microwave radiation and its effects on the adsorption of methylene blue. Appl. Surf. Sci. 2010, 256, 3309-3315. [CrossRef]

49. Wang, Y.X.; Liu, B.S.; Zheng, C. Preparation and adsorption properties of corncob-derived activated carbon with high surface area. J. Chem. Eng. Data 2010, 55, 4669-4676. [CrossRef]

50. Liou, T. Development of mesoporous structure and high adsorption capacity of biomass-based activated carbon by phosphoric acid and zinc chloride activation. Chem. Eng. J. 2010, 158, 129-142. [CrossRef]

(C) 2017 by the authors. Licensee MDPI, Basel, Switzerland. This article is an open access article distributed under the terms and conditions of the Creative Commons Attribution (CC BY) license (http:/ / creativecommons.org/licenses/by/4.0/). 